\title{
Advance care planning in progressive neurological diseases: lessons from ALS
}

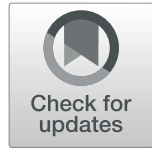

Antje A. Seeber ${ }^{1,2^{*}}$, A. Jeannette Pols ${ }^{2}$, Albert Hijdra ${ }^{1}$, Hepke F. Grupstra ${ }^{3}$, Dick L. Willems ${ }^{2}$ and Marianne de Visser ${ }^{1}$

\begin{abstract}
Background: There is increasing awareness of the need for an integrated palliative care approach in chronic progressive neurological diseases. Advance care planning (ACP) is an integral part of this approach. As a systematically organized and ongoing communication process about patients' values, goals and preferences regarding medical care during serious and chronic illness, ACP aims to involve patients in decision-making before they become cognitively and communicatively incapable. However, it remains underutilized in daily neurological practice except for speciality clinics such as ALS centers. Our aim was to study ACP in the tertiary ALS center Amsterdam and to investigate patients' reflections on it. Subsequently we used this knowledge to formulate recommendations for integration of ACP in the care of patients with other chronic progressive neurological diseases.

Methods: Non-participating observations of all appointments of patients with amyotrophic lateral sclerosis (ALS) or progressive muscular atrophy (PMA) with the treating physician, in various stages of disease, during 6 consecutive months, followed by single in-depth interviews, and an inductive analysis.

Results: Twenty-eight Dutch patients participated, varying in age, gender, disease onset and severity of physical decline. ACP started directly when the diagnosis was given, by means of a general outlook on the future with progressive disability and immediate introduction to a customized multidisciplinary team. During follow-up ACP was realized by regular appointments in which monitoring of the patient's status and clear communication strategies formed the basis of tailor-made discussions on treatment options. Patients accepted this policy as careful professional guidance.

Conclusions: ACP is a professional communication process throughout the whole course of progressive disease. It is feasible to integrate ACP into follow-up of patients with ALS and PMA from diagnosis onwards. Supported by recent literature, we argue that such a well-structured approach would also enhance the quality of care and life of patients with other chronic progressive neurological diseases.
\end{abstract}

Keywords: Advance care planning, Chronic progressive neurological disease, Supportive and palliative care, Quality of life

\section{Background}

Chronic progressive neurological diseases (CPNDs) are associated with increasing disability and shortened life expectancy [1]. Patients with conditions such as amyotrophic lateral sclerosis (ALS), high grade glioma (HGG), multiple sclerosis (MS), Parkinson's disease (PD) and other movement disorders, post-stroke status with disability, and dementia syndromes share a host of physical,

\footnotetext{
*Correspondence: a.a.seeber@amc.uva.nl

'Department of Neurology, Amsterdam University Medical Center, Academic Medical Center, University of Amsterdam, P.O. Box 22660, 1100 DD

Amsterdam, The Netherlands

${ }^{2}$ Section of Medical Ethics, Department of General Practice, Amsterdam

University Medical Center, Academic Medical Centre, University of

Amsterdam, P.O. Box 22660, Amsterdam, The Netherlands

Full list of author information is available at the end of the article
}

emotional, and existential problems, and unmet care needs which require an integrated palliative care approach [2-6]. Advance care planning (ACP) is an integral part of this approach. It can be summarized as systematically organized and ongoing 'process of communication to ensure that patients receive medical care that is consistent with their values, goals and preferences during serious and chronic illness' [7]. Its goal is involvement of patients in decision-making on (future) care before these patients become cognitively and communicatively incapable to do so $[8,9]$.

However, ACP is underutilized in both non-neurological and neurological diseases [3, 10-13]. This may result in under- and overtreatment and poor quality of life and

(c) The Author(s). 2019 Open Access This article is distributed under the terms of the Creative Commons Attribution 4.0 International License (http://creativecommons.org/licenses/by/4.0/), which permits unrestricted use, distribution, and 
dying [14-17]. The underutilization appears to be mainly due to misconceptions about and unfamiliarity with palliative care, including the concept and goal of ACP [18-22].

In the Netherlands' ALS tertiary center (NAC), ACP is commonly practiced. The rapid progression of ALS and progressive muscular atrophy (PMA) tolerates no delay in discussing personal values, life goals, and preferences regarding (future) medical care. In ALS, 50\% of patients die within 36 months after symptom onset and in PMA within 48 months [23, 24]. Death is usually caused by respiratory failure as a result of progressive muscle weakness [25]. The only currently available disease-modifying drugs, riluzole, prolongs life by only a few months. The added value of edavarone is still a matter of debate [26, 27]. Supportive interventions including feeding via a gastrostomy tube (percutaneous endoscopic gastrostomy, PEG) and non-invasive ventilation do not prevent severe and progressive disability either [28, 29]. However, they are associated with prolonged survival and/or improved health-related quality of life and therefore recommended to be offered to patients with MND, in a timely manner [4, 30, 31].

We set out to explore how ACP is realized in this special setting. Our main aims were (1) to evaluate timing and content of discussions on supportive treatment options and end-of-life care and to investigate patients' reflections on this practice, and (2) to formulate recommendations about integration of $\mathrm{ACP}$ in the care of patients with other CPNDs.

\section{Methods}

We performed an inductive content analysis of observations and interviews and present our data according to the Consolidated Criteria for Reporting Qualitative Research (COREQ, Additional file 1: Table S1 [32]).

\section{Setting}

In the tertiary ALS center of the Academic Medical Center of Amsterdam (AMC) the bad news is broken in a two-tiered appointment: a neurologist specialised in motor neuron diseases (MNDs) delivers the bad news and discusses the details of the diagnosis and its implications during a follow-up visit 2 weeks later [22]. At that very time follow-up by a multidisciplinary team specialised in MND is initiated via an appointment with the team leader, a specialized rehabilitation physician. During regular three-monthly follow-up, commonly lasting an hour, the lead of the team takes the recent history including evaluation of paramedical support and scores the actual ALS-Functional Rating Scale. The physical examination includes measurement of weight and assessment of lung function by means of slow vital capacity (VC, a measure of breathing).

\section{Study design}

All participants were followed during a 6 months' period by means of non-participating observations by the first author (AAS) of all appointments with the specialist in charge, either from breaking the bad news onwards, at relatively early stages of disease (group 1; seen first by the neurologist and subsequently by the rehabilitation physician during the observation period) or during more advanced stages of disease (group 2; seen by the rehabilitation physician during the observation period). The in-depth interview with every participant took place within several weeks after the observation period of 6 months.

\section{Participants}

We included adult patients with ALS or PMA, seeking broad variation concerning the characteristics 'age,' 'gender', 'site of disease onset,' 'severity of disease' and 'rate of physical decline' (purposive sampling [33]). We considered these features to be important and rather easily accessible variables which influence patients' experiences and reflections and thus contribute to the heterogeneity of the sample. Patients needed to be fluent in Dutch. Speech impairment was no exclusion criterion as long as communication remained possible (e.g. with the help of a speech computer). The only exclusion criterion was frontotemporal dementia. Eligible patients were first approached by either the neurologist (group 1) or the specialised nurse of the multidisciplinary MND team (group 2), and were informed about the study. When the patient showed interest, he/she was asked for verbal consent to be contacted by the first author (AAS). She would give more detailed information about the study, verbally and in writing, and ask patients for written informed consent. Patients knew that they could withdraw from the study at any moment, without explanation. Furthermore, it was guaranteed that no information obtained during the interview would be shared with anyone of the treating medical team.

\section{Ethics approval}

All patients gave written informed consent. Dutch law specifies that ethics approval is only needed when 'participants are subject to procedures or are required to follow rules of behaviour' (https://english.ccmo.nl/ investigators/legal-framework-for-medical-scientific-research/your-research-is-it-subject-to-the-wmo-or-not). As this was not the case, the approval of the local research ethics committee (REC) was waived, as confirmed in writing (14th June 2010). Participants were offered contact with the researcher or a member of their ALS team if participation in the study led to any questions or concerns. 


\section{Data collection}

The first author (AAS) collected the data between August 2011 and November 2012. During the observations of the appointments of patients with ALS/PMA and their MND specialist (to which we will refer as 'observations') she took extensive field notes which she worked out immediately afterwards. The second author (AJP) read all field notes and marked and labelled emerging themes, as did the first author. After reaching consensus about important themes, the first author explored and validated these during the observations which followed. For the interviews, the first and second author used an iterative method too, adapting and accentuating the semi-structured interview guide, first developed based on key concepts identified in the literature and during the observations. Furthermore, the interviewer added questions concerning each interviewed patient's personal illness trajectory to the individual patient's topics list. All interviews took place at the patients' preferred location and time.

\section{Analysis}

Observations were recorded and anonymized, interviews were audio-recorded, typed out verbatim, and anonymized by the first author who saved all original data on an external hard disc. Observation reports and transcripts were analyzed using MAXqda version 10 software [34]. The interviewer coded characteristics of the appointments and patients' opinions concerning these characteristics, such as 'general outlook on the future' and 'rituals during regular follow-up'. This was done shortly after each observation and interview, so that findings could be iteratively fed into the evolving coding tree and interview guide.

To ensure that the data analysis would accurately reflect reality, the second author validated the whole analytic process by reading all transcripts and took an active part in (sub)coding as described above. The first author (AAS) also discussed the codes with research colleagues from multiple backgrounds involved in other qualitative studies (investigator triangulation [35]). The whole process ended when saturation was reached, i.e. when no new categories or variations were needed to address the main research questions. The lists of transcripts under each code served for further analysis following the qualitative approach of empirical ethics [36].

\section{Results}

Ten patients were observed from disclosure of the diagnosis onwards (group 1), 18 patients during later stages of follow-up (group 2). Twenty-one of these 28 patients were interviewed (Table 1), the seven remaining patients were no longer able to participate since they were too ill to communicate (6) or had died (1; Additional file 2: Table S2).

All 21 interviewed patients were born and raised in the Netherlands. Sixteen interviews were held in the presence of
Table 1 Characteristics of interviewed patients

\begin{tabular}{lll}
\hline Number of interviewees & with ALS/PMA & $16 / 5$ \\
\hline Gender & male/female & $13 / 8$ \\
Age (range 36-83 years) & $<55$ years & 7 \\
& 55-65 years & 9 \\
& $>65$ years & 5 \\
Disease onset & limb/bulbar & $17 / 4$ \\
Functional stage (when & ALS-FRS $\geq 40$ (including dysarthria ${ }^{a}$ ) & $5(1)$ \\
interviewed) & ALS-FRS 31-39 (including dysarthria $\left.{ }^{a}\right)$ & $8(2)$ \\
& ALS-FRS $\leq 30$ (including dysarthria ${ }^{a}$ ) & $8(4)$
\end{tabular}

ALS Amyotrophic lateral sclerosis, PMA Progressive muscular atrophy, ALS-FRS ALS functional rating scale (maximum score: 48; a higher score represents better function retention); ${ }^{a}$ moderate or severe dysarthria

the patients' partners or other relatives who actively took part in the conversation. All interviews took place at the patients' home and lasted between 45 and 120 min. Patients with (severe) impairment of speech used a chalkboard, a laptop or a speech computer. After 16 interviews no evidently new information regarding our main research questions emerged and after an additional five interviews thematic saturation was reached. No patient or relative voiced any concern about the study during or after participation.

\section{In the beginning}

Advance care planning started as soon as the diagnosis ALS or PMA was disclosed. During two appointments within 2 weeks (two-tiered bad news appointment) the neurologist gave a rather general outlook on the future with progressive physical decline, care needs and supportive treatment options [22]. The rehabilitation physician with MND-expertise who directly took over further followup, repeated the information once again integrating it in a more concrete outlook on the regular consultations to follow in the outpatient clinic.

There are many things which we cannot predict, but what we do know is that the disease has a constant progression. There will be no sudden surprises, e.g. total paralysis within a couple of days. (Observation patient 3 , second appointment with the MND neurologist)

We will monitor your weight and the strength of your breathing muscles. You will be asked to stand on the scales and blow into this device (spirometer) during each check-up. Eating and breathing are the most vulnerable functions. We can assist these functions if problems arise, but in order to do so we need to know if a problem is developing. (Observation patient 4, first appointment with the MND rehabilitation physician)

According to many interviewees, it was crucial that this general outlook on possible future care needs and 
options was embedded in the information on the ongoing support which would be provided by the multidisciplinary ALS team.

\section{It helped me, quite confused as I was at that time, to learn that there was a team that would help me, support me, people with a plan... and, of course, knowledge about the disease... (Interview patient 13)}

If patients suffered from potentially life-threatening symptoms by the time of diagnosis, such as severe shortness of breath or imminent choking, both the MND neurologist and the rehabilitation physician would directly provide detailed information about possible treatment options to enable decision-making without delay.

I am very worried about your shortness of breath. You mentioned that you can only sleep at night in a sitting position. I am referring you directly to the pulmonology department to see how exhausted the respiratory muscles are. After that we can talk about the possibility of assisting these muscles. I am afraid we will have to make some important decisions today; do you think you are up to this? (Observation patient 10, first appointment with the MND neurologist)

This policy appeared to fit with the patients' tendency to ask detailed information mostly about actual disabling complaints.

Nearly all patients used the first appointments to address the issue 'treatment wishes for the end of life'. Some patients immediately provided fully filled-in living wills and patient testaments. During the observations, we noticed that only patients raised the issue of 'euthanasia'. Discussing the content and meaning of the - documented - wishes often revealed patients' profound fear to choke or to stay alive in a miserable condition, and also patients' hope to stay in control of any future scenario by documenting their preferences.

\section{I immediately discussed the euthanasia declaration with my general practitioner. I wanted to know whether she would help me. Otherwise, I had had to look for another GP... I have a feeling of peace now that this [euthanasia declaration] is in place. \\ (Interview patient 5)}

Nineteen of the participating 28 patients (68\%) signed a euthanasia statement. Eighteen did so within the first weeks after consultation of their general practitioner (GP), the remaining one within 6 months after diagnosis. Twenty-one of the participating 28 patients have passed away in the meantime. Fifteen of them had signed the statements, and five of them eventually requested euthanasia (23\% of the deceased, $33 \%$ of those who had signed an euthanasia declaration) (Additional file 2: Table S2).

The rehabilitation physician encouraged patients to think about treatment preferences, including advance directives (AD) and support at the end of life, and to discuss these with significant others and the general practitioner. However, he did not consistently discuss these issues as long as patients did not have potentially life-threatening symptoms. With regard to decisionmaking on artificial nutrition and ventilation support he emphasized that it was important to keep on discussing these throughout the disease trajectory.

It is important for me to hear how you feel about certain modalities of treatment. However, there are some decisions which you cannot easily make in advance, they can only be made when the time comes. I do not think it would be useful to decide now that you do not wish, under any circumstances, to be given any assistance in breathing should you experience shortness of breath. (Observation patient 15, follow-up appointment with MND rehabilitation physician)

Let's agree to discuss your advance directive again in a couple of months' time. I want to make sure that I stay up to date with your wishes. (Observation patient 27, follow-up appointment with MND rehabilitation physician)

Interviewees often talked about the 'natural' way in which both MND neurologist and rehabilitation physician directly integrated information on possible physical decline, care needs and supportive treatment options in the consultations. Several of them explicitly stated that it made them feel at ease and enabled them to raise awkward or very personal issues and fears about the future.

The neurologist immediately said that the team would arrange for me to stay at home if that was my wish. He had no preconceived plan of his own, and he did not think my questions were ridiculous.... (Interview patient 12)

\section{During the illness trajectory}

During the three-monthly follow-up visits, the recent patient history was taken and the functional status was measured by the ALS-FRS. At each visit physical examination was performed including monitoring of weight and $\mathrm{VC}$. If changes in one or more of these parameters indicated evident physical decline, the MND rehabilitation physician 
took the initiative to discuss supportive treatment options in more detail.

As an example: in a patient with decreasing VC (between 100 and $70 \%$ of normal), the MND rehabilitation physician first gave information about the different treatment options, i.e., 'non-invasive', 'invasive' and 'no ventilatory support', and asked if the patient had already thought about his preferences. During the next appointment he advised consultation of a specialist in a home care ventilation centre when he learned that the patient was interested in ventilatory support. After that consultation, he reflected on the advice of the home care ventilation centre and the patient's considerations and decision. He applied the same step-by-step approach concerning other supportive treatment options such as 'PEG' and care equipment options such as 'triple chair'.

You are spending all day trying to consume enough calories. From what you say there is barely time left for anything else. During your last visit we briefly discussed the possibility of a 'PEG' feeding tube. How do you feel about this, have you had a chance to think it over? Would you like to receive more information about it from our gastro-enterologist, who would place the tube? (Observation patient 18, follow-up appointment with MND rehabilitation physician)

Walking has deteriorated further, I stumble more often and that makes me very unsure, but I really want to keep walking my dog! - Have you considered whether using a wheelchair for outdoor activities would be an option? You see, it would take some time before it was delivered and perhaps it would just gather dust in the cellar, but it would be there should you want to use it to walk the dog... (Observation patient 11, follow-up appointment with MND rehabilitation physician)

Most patients made it clear that detailed information about supportive medical treatment options was only experienced as truly meaningful when it fitted with the perception of their own physical and psychosocial condition. A few patients expressed their annoyance if in their opinion the information was untimely.

I had problems with swallowing, but could still eat reasonably well. Discuss energy drinks with a dietician? Absolutely not! But now, I am quite happy with her [dietician] advice... Did you know that there are energy drinks which are quite palatable?

(Interview patient 3)

I wanted to have everything arranged immediately. On reflection perhaps it would have been better if they had not tried to address all my concerns. A wheelchair was delivered to the house straight away .... Not very pleasant when you do not need it yet. (Interview patient 14)

In line with that, the patients usually initiated discussions about supportive treatment options in relation to experienced physical decline, and tended to ask for more detailed information when physical restraints started interfering with their daily habits and way of life. Additionally, social events such as birthdays, Christmas, New Year's Eve, but also illness and death of significant others, made patients reflect on their future with the ongoing disease.

I refer to it as 'looking just beyond the horizon together'. That is what I can cope with and that is what we do together during the consultation. Looking beyond that is too painful (...) Looking further would also mean that I cannot really talk about myself (....) If you can still walk short distances, it is perhaps reassuring to know that you can at some point order a wheelchair. But it is not until you are no longer able to support your head that you are keen to know which headrests are compatible with your wheelchair. (Interview patient 7)

The MND rehabilitation physician always discussed resuscitation orders by the time respiratory problems arose since they predict weaning difficulties after a potential resuscitation with intubation. The majority of the participants had filled out advance directives (ADs) by that time.

Once set on the agenda, the MND rehabilitation physician addressed both supportive treatment options and ADs regularly. That could be due to further physical decline requiring very concrete information and definite decisions or due to time passing by requiring an update of the patient's actual treatment preferences.

Patients were always advised to keep an up-to-date written document with them, and (changes of) patients' preferences regarding future and end-of-life care were always reported to the GPs.

Some patients did not want to think ahead at all. In these cases, the physician asked permission to at least once talk about concrete treatment options when physical deterioration became prominent. He justified that by stating that 'a good healthcare professional should provide patients with sufficient information to enable them to make well-informed treatment decisions'.

I feel that I am obliged to know what your true wishes are, particularly in order to prevent things from happening which you do not want. Am I correct in thinking that you find it difficult to discuss such things [Do Not Resuscitate]? Shall we agree that I will come back to the subject in 6 months' time? And that I will 
let you know when I am going to do this? (Observation patient 26, follow-up appointment with the MND rehabilitation physician)

For most patients, the step-by-step approach to tailormade supportive medical care, including a regular update on advance directives, appeared to work well. Last but not least, the anticipatory policy of the whole ALS team enabled them to become experts themselves who knew when to raise alarm.

I notice that I get tired more quickly during the day, even if I'm only fumbling around at home. But I am not worried that my breathing is compromised. I do not have a headache when I wake up. And my vital capacity is also good. She (specialized nurse of the outpatient clinic) has just measured it, and I still score $110 \%$. (Observation patient 1, follow-up appointment with the MND rehabilitation physician)

However, this policy did not prevent that two of the participating patients were admitted to the emergency department in respiratory failure without a clear treatment plan. One patient had procrastinated for too long, and one patient had an unexpectedly rapidly progressive decline. The latter was intubated against her earlier expressed will as she had no (actual) advance directive present when she abruptly became dyspnoeic.

Furthermore, interviewees acknowledged that the visits to the office became more confronting as their condition worsened. For example, learning that the $\mathrm{VC}$ had further decreased and thus decision-making about ventilatory support could not be postponed anymore could be terrifying. Nevertheless, none of the patients could think of an alternative, or a 'better' solution.

At the beginning you think 'yes, everything is fine', but at a certain moment the lung function does start to deteriorate and you know that of course. At the outpatient clinic you are given the hard facts, I always need some time to recover from that... (Interview patient 21)

It is important to stay in contact with someone who knows who you are and what you stand for, even if you can no longer express yourself fully. (Interview patient 20)

The interviewees said that they understood why issues about supportive medical treatment options, including the end-of-life, were regularly put on the agenda. Several interviewees explicitly stated that it was the doctor's duty to carefully check for emerging (physical) problems and have discussions about the implications.

\section{Discussion}

The policy of the Dutch ALS outpatient clinic is to initiate advance care planning (ACP) directly when the diagnosis is delivered. On that occasion, a general outlook on the future with progressive diseases and probable care needs is given by the specialized neurologist, and an introduction to a customized multidisciplinary support team at short notice is organized. During follow-up, ACP is realized by regular appointments in which both monitoring of the patient's status quo and clear communication strategies form the basis of iterative and tailor-made discussions on future supportive treatment. Patients appeared to accept this policy as part of the MND specialists' professional guidance throughout the illness trajectory.

ACP as realized in the studied tertiary ALS center complies with current international recommendations on the management of MNDs. These include (1) a palliative care approach early in the course of disease, including (2) ongoing open communication and clear identification of important issues related to (end-of-life) decision-making, (3) a calm environment where time is allowed for reflection and integration of choices according to the patient's priorities and life plans [4, 14, 37]. Importantly, recent studies show that even in ALS, the 'paradigm [disease] for palliative care in neurology', proper, i.e. broad implementation of these recommendations has not yet been achieved [38, 39]. In line with that our data show that ACP 'by the book' demands a very well-organized and dedicated care team. Still, we argue that our empirical data enable us to formulate some pragmatic recommendations for early integration of ACP in the follow-up of patients with other CPNDs.

\section{ACP - from diagnosis of any progressive chronic neurological disease onwards}

We argue that ACP as an ongoing communication process about patients' goals and treatment preferences should start as soon as the diagnosis of any chronic progressive neurological disease is given. There is a lack of empirical data on patients' preferences regarding exact timing and detailedness of prognosis and treatment information. However, recent studies indicate the need of patients with e.g. HGG, MS, PD for proactive dissemination of information, education and (psychosocial) support [40-45]. Moreover, patients expect their physicians to initiate these discussions [41, 46-48]. The rather long and often unpredictable course of diseases such as MS and PD does not imply that patients have less information and support needs. In addition, at the time of diagnosis, patients with these diseases face a similar crisis as patients who are confronted with the diagnosis ALS or cancer [49-51]. In general, patients are overwhelmed by the bad news, need time to take in the medical information and to reflect on it. Follow-up at short notice 
appears to be helpful in establishing a better understanding of what the diagnosis 'incurable disease' means in the individual context [52]. In addition, it can help in establishing a communication basis for long-term follow-up, as it minimizes patients' feelings of abandonment [22, 53]. Another compelling argument to directly start ACP is the fact that patients with various CPNDs may face impairment of cognition and hence decision-making capacity from early stages of disease onwards [54-59].

\section{ACP - during long-term follow-up}

Our data indicate that the clearly structured follow-up of patients with MND facilitates maintenance of ACP. Our participants counted on the regular check-up of their overall health status and knew that (imminent) deterioration would lead to more detailed discussions about future supportive treatment options. Therefore, we recommend a similar regular assessment of patients with any other progressive chronic neurological disease. This assessment should address both disease-specific and commonly occurring disease-related symptoms such as pain, fatigue and cognitive problems. The latter problems can also occur early in the course of e.g. MS, PD and gliomas and have been found to be among the most function and quality-of-life limiting $[48,60,61]$. As we have shown and will discuss in more detail in the next paragraph, regular assessment would facilitate ongoing considerations and discussions about end-of-life wishes including documentation in ADs. In line with recent literature, our study indicates that ACP empowers patients to face the progression of disease. Timely information about their own health status in the context of knowledge on prognosis and upcoming supportive treatment decisions seems to make patients less anxious [62-64].

\section{ACP - a professional skill}

Our data contributes to the concept of ACP in terms of concrete, routinely used communication strategies. Always 'setting the agenda' facilitated preparing the biannual update on earlier discussed advanced directives (ADs) during the next appointment. It made readdressing the topic less delicate for both parties. Furthermore, the iterative evaluation of actual wishes supported the realization of well-considered care trajectories $[15,65]$. The titration of information to patients' actual health status and symptom burden, called 'looking just beyond the horizon' by one of the patients, allowed the specialist to stay close to how the individual patient perceived his or her situation. It also made exchange of medical information meaningful and facilitated tailor-made decisions. It has been shown before that titration of medical information and support fits well with the ongoing adaptation to deteriorating abilities of patients with ALS [52, 66, 67]. As discussed above, we recommend that tailor- made exchange of information is equally needed for patients with other CPNDs [3, 48, 68].

$\mathrm{ACP}$ is a fundamental palliative care skill, just like communicating bad news and assessing (non-)motor symptom [3]. Recent literature suggests that the majority of physicians lack these skills [53,69-71]. Yet, there is growing evidence that teaching programs do improve physicians' communication strategies and overall satisfaction with handling difficult disease-related topics [7276]. Thus, ongoing professional training in both iterative assessment of patients' health status and supportive care needs and communication (strategies) is required in dealing with patients with CPNDs. Mastering these skills will facilitate ACP as part of good long-term care for patients with these diseases.

\section{Strengths and limitations}

One strength of our study is that we observed at least three outpatient clinic appointments of all 28 participating patients in different stages of disease and that we interviewed 21 of them in depth. Participants were of different ages, gender, and had different illness trajectories. This all led to a wealth of data with consistent conclusions concerning ACP and participants' experiences. As only one of the patients declined participation in the study, a significant selection bias is unlikely. Since interviewer and interviewees were acquainted with each other by the time the interview took place and patients' carers were allowed to attend the interview, patients may have felt comfortable to openly and critically talk about their experiences.

A limitation of our study is that it took place in a single tertiary referral centre located in the Netherlands, where end-of-life considerations, including hastened death, are openly discussed. Most patients who were observed and all patients who were interviewed have been born and raised in the Netherlands. Most observations took place during the follow-up visits which were done by the only MND rehabilitation physician of the team and the specialised nurse. The role of other (para)medics and of the caregivers was not evaluated. Neuropsychological tests were not performed and the carers were not asked about the patient's behaviour, leaving (subtle) cognitive and behavioural changes undetected. However, we did rule out frank dementia. Acquaintance with the interviewer and presence of patients' carers during the interview might also have elicited socially desirable answers. Furthermore, one of the authors is involved in the patient care at the centre.

There is few empirical data on ACP in actual practice. The approach of the tertiary ALS center Amsterdam appears to be feasible from diagnosis onwards. However, we are aware of the challenges to realize ACP for patients with other CPNDs. There are important questions about the organization of these patients' long-term follow-up, in particular the responsibilities of the involved health care 
professionals for timely assessment and treatment of palliative care needs. Furthermore, there is a wide variation in individual illness trajectories amongst various CPNDs which requires both disease-specific and in the individual patient health-status related support in daily clinical practice [2]. Patients with PD or MS, for example, will have very different information and support needs during successful treatment with disease-specific and immunemodulating treatment as compared to late stages of diseases when non-disease specific symptom alleviation will be more and more challenging $[41,77,78]$. We also noticed that in the presented approach there is room for improvement. The MND rehabilitation physician did regularly stimulate discussions about ADs such as do-notresuscitate orders, but he did not readdress the euthanasia statements which patients provided. These were, without exception, discussed with the GP, interestingly mostly within the very first weeks after the diagnosis was given. This may well reflect the need to (re)gain control about the disease process including death at a time when patients expect to be totally out of control, but further research on this topic is needed [79]. Thirty-three percent of all participating patients who had signed that statement eventually requested euthanasia and died at home. The latter - counselling on the preferred place of dying - was another topic which could have been more specifically addressed.

\section{Conclusion}

Our data contributes to increasing awareness that ACP is feasible from the ALS diagnosis onwards and may well be implemented in the care of patients with other CPNDs. We have shown that ACP is more than a distinct activity to make well-informed decisions on future treatment options and end-of-life issues [21]. ACP is a distinctive feature of good care and requires professional skills.

\section{Additional files}

Additional file 1: Table S1. 32-item checklist of the COREQ. (DOCX $15 \mathrm{~kb}$ ) Additional file 2: Table S2. Characteristics of all Dutch participants. (DOC $78 \mathrm{~kb}$ )

\section{Abbreviations \\ ACP: Advanced care planning; AD: Advance directive; ALS: Amyotrophic lateral sclerosis; CPND: Chronic progressive neurological disease; GP: General practitioner; HGG: High grade glioma; MND: Motor neuron disease; MS: Multiple sclerosis; NAC: Netherlands' ALS tertiary center; PD: Parkinson's disease; PEG: Percutaneous endoscopic gastrostomy; PMA: Progressive muscular atrophy; VC: Vital capacity}

\section{Acknowledgements}

The authors would like to thank the participating patients with MND and their carers for their time and frankness in the interviews, and J.C.M. Borger, the specialised nurse of the same multidisciplinary MND team, for her assistance in recruiting participants. Furthermore, we are grateful for the important recommendations by prof. G.D. Borasio on an earlier draft of this paper.

The results of our study of 'ACP in practice' were discussed during a poster presentation of the 29th International Symposium on ALS/MND in Glasgow 2018.

\section{Authors' contributions}

AAS set up and performed the study, drafted the manuscript and wrote the final version of the paper. AJP supervised the study, drafted and revised the manuscript. AH drafted and revised the manuscript. HJG and DLW revised the manuscript. MdV supervised the study, drafted and revised the manuscript. All authors read and approved the final manuscript.

\section{Funding}

The Netherlands Organization for Health Research and Development (ZonMw). This organization was not involved in any part of the study.

\section{Availability of data and materials}

The dataset generated and analyzed during the current study are not publicly available. They are in Dutch language and available from the corresponding author on request.

Ethics approval and consent to participate

All patients gave written informed consent. Dutch law specifies that ethics approval is only needed when 'participants are subject to procedures or are required to follow rules of behaviour' (https://english.ccmo.nl/investigators/ legal-framework-for-medical-scientific-research/your-research-is-it-subject-tothe-wmo-or-not). As this was not the case, the approval of the local research ethics committee (REC AMC Amsterdam) was waived, as confirmed in writing.

\section{Consent for publication}

We obtained written informed consent of all patients to use their anonymized data for research articles, teaching and - if applicable development and revision of guidelines.

\section{Competing interests}

The authors declare that they have no competing interests.

\section{Author details}

${ }^{1}$ Department of Neurology, Amsterdam University Medical Center, Academic Medical Center, University of Amsterdam, P.O. Box 22660, 1100 DD Amsterdam, The Netherlands. ${ }^{2}$ Section of Medical Ethics, Department of General Practice, Amsterdam University Medical Center, Academic Medical Centre, University of Amsterdam, P.O. Box 22660, Amsterdam, The Netherlands. ${ }^{3}$ Department of Rehabilitation, Amsterdam University Medical Center, Academic Medical Center, University of Amsterdam, P.O. Box 22660 Amsterdam, The Netherlands.

Received: 4 January 2019 Accepted: 27 May 2019

Published online: 13 June 2019

\section{References}

1. Pakpoor J, Goldacre M. Neuroepidemiology: the increasing burden of mortality from neurological diseases. Nat Rev Neurol. 2017;13(9):518-9.

2. Dallara A, Tolchin DW. Emerging subspecialties in neurology: palliative care. Neurology. 2014;82(7):640-2.

3. Boersma I, Miyasaki J, Kutner J, Kluger B. Palliative care and neurology: time for a paradigm shift. Neurology. 2014;83(6):561-7.

4. Oliver DJ, Borasio GD, Caraceni A, de Visser M, Grisold W, Lorenzl S, et al. A consensus review on the development of palliative care for patients with chronic and progressive neurological disease. Eur J Neurol. 2016;23(1):30-8.

5. Ostgathe C, Gaertner J, Kotterba M, Klein S, Lindena G, Nauck F, et al. Differential palliative care issues in patients with primary and secondary brain tumours. Support Care Cancer. 2010;18(9):1157-63.

6. Voltz R, Bernart JL, Borasio GD, Maddocks I, Oliver D, Portenoy RK. Palliative care in neurology. Oxford: Oxford University Press; 2004.

7. Sudore RL, Lum HD, You JJ, Hanson LC, Meier DE, Pantilat SZ, et al. Defining advance care planning for adults: a consensus definition from a multidisciplinary Delphi panel. J Pain Symptom Manag. 2017;53(5):821-32.e1. 
8. Sizoo EM, Grisold W, Taphoorn MJ. Neurologic aspects of palliative care: the end of life setting. Handb Clin Neurol. 2014;121:1219-25.

9. Andreassen P, Neergaard MA, Brogaard T, Skorstengaard MH, Jensen AB. The diverse impact of advance care planning: a long-term follow-up study on patients' and relatives' experiences. BMJ Support Palliat Care. 2017;7(3):335-40.

10. De Vleminck A, Pardon K, Beernaert K, Deschepper R, Houttekier D, Van Audenhove $C$, et al. Barriers to advance care planning in cancer, heart failure and dementia patients: a focus group study on general practitioners' views and experiences. PLoS One. 2014;9(1):e84905.

11. Denvir MA, Murray SA, Boyd KJ. Future care planning: a first step to palliative care for all patients with advanced heart disease. Heart. 2015; 101(13):1002-7.

12. Johnson S, Butow P, Kerridge I, Tattersall M. Advance care planning for cancer patients: a systematic review of perceptions and experiences of patients, families, and healthcare providers. Psychooncology. 2016;25(4):362-86.

13. Walter HAW, Seeber AA, Willems DL, de Visser M. The role of palliative care in chronic progressive neurological diseases - a survey amongst neurologists in the Netherlands. Front Neurol. 2018;9:1157.

14. Connolly S, Galvin M, Hardiman O. End-of-life management in patients with amyotrophic lateral sclerosis. Lancet Neurol. 2015;14(4):435-42.

15. Mullick A, Martin J, Sallnow L. An introduction to advance care planning in practice. BMJ. 2013;347:f6064

16. Temel JS, Greer JA, Muzikansky A, Gallagher ER, Admane S, Jackson VA, et al. Early palliative care for patients with metastatic non-small-cell lung cancer. N Engl J Med. 2010;363(8):733-42.

17. Tulsky JA. Decision-making in serious illness: a matter of life, death and words. Patient Educ Couns. 2010;80(1):1-2.

18. Golla H, Ebke M, Rolke R, Lorenzl S, Nacimiento W, Thiekotter T, et al. Integration of palliative and hospice care structures in the care of neurological patients: opinion of chief consultant neurologists in Germany. Fortschr Neurol Psychiatr. 2016;84(12):733-8.

19. Heyland DK, Cook DJ, Rocker GM, Dodek PM, Kutsogiannis DJ, Skrobik Y, et al. Defining priorities for improving end-of-life care in Canada. CMAJ. 2010; 182(16):E747-52.

20. Howard M, Bernard C, Tan A, Slaven M, Klein D, Heyland DK. Advance care planning: let's start sooner. Can Fam Physician. 2015;61(8):663-5.

21. Mitchell SJ, Dale J. Advance care planning is everybody's business. BMJ. 2013;347:f6748

22. Seeber AA, Pols AJ, Hijdra A, Grupstra HF, Willems DL, de Visser M. Experiences and reflections of patients with motor neuron disease on breaking the news in a two-tiered appointment: a qualitative study. BMJ Support Palliat Care. 2016;0:e1-9.

23. Kim WK, Liu X, Sandner J, Pasmantier M, Andrews J, Rowland LP, et al. Study of 962 patients indicates progressive muscular atrophy is a form of ALS. Neurology. 2009;73(20):1686-92.

24. Van den Berg-Vos RM, Visser J, Kalmijn S, Fischer K, de Visser M, de Jong V, et al. A long-term prospective study of the natural course of sporadic adultonset lower motor neuron syndromes. Arch Neurol. 2009;66(6):751-7.

25. Mitsumoto H, Chad D, Pioro EP. Amyotrophic lateral sclerosis. Philadelphia: F.A. Davis Company; 1998.

26. Miller RG, Jackson CE, Kasarskis EJ, England JD, Forshew D, Johnston W, et al. Practice parameter update: the care of the patient with amyotrophic lateral sclerosis: multidisciplinary care, symptom management, and cognitive/behavioral impairment (an evidence-based review): report of the quality standards Subcommittee of the American Academy of neurology. Neurology. 2009;73(15):1227-33.

27. Writing G, Edaravone ALSSG. Safety and efficacy of edaravone in well defined patients with amyotrophic lateral sclerosis: a randomised, doubleblind, placebo-controlled trial. Lancet Neurol. 2017;16(7):505-12.

28. Radunovic A, Annane D, Jewitt K, Mustfa N. Mechanical ventilation for amyotrophic lateral sclerosis/motor neuron disease. Cochrane Database Syst Rev. 2009;(4). https://doi.org/10.1002/14651858.CD004427.pub2.

29. Spataro R, Ficano L, Piccoli F, La Bella V. Percutaneous endoscopic gastrostomy in amyotrophic lateral sclerosis: effect on survival. J Neurol Sci. 2011;304(1-2):44-8.

30. Bourke SC, Gibson GJ. Non-invasive ventilation in ALS: current practice and future role. Amyotroph Lateral Scler Other Motor Neuron Disord. 2004;5(2):67-71.

31. Carratu P, Spicuzza L, Cassano A, Maniscalco M, Gadaleta F, Lacedonia D, et al. Early treatment with noninvasive positive pressure ventilation prolongs survival in amyotrophic lateral sclerosis patients with nocturnal respiratory insufficiency. Orphanet J Rare Dis. 2009;4:10.
32. Tong A, Sainsbury P, Craig J. Consolidated criteria for reporting qualitative research (COREQ): a 32-item checklist for interviews and focus groups. Int J Qual Health Care. 2007;19(6):349-57.

33. Lucassen P. olde Hartman T. Qualitative research. Pratical methods for daily practice (Kwalitatief onderzoek. Praktische methoden voor de medische praktijk [in Dutch]). Houten: Bohn Stafleu van Loghum; 2007.

34. MAXqda. The art of text analysis. VERBI software (Consult. Sozialforschung GmbH). Berlin: VERBI Software GmbH; 2010. https://www.maxqda.com/ contact/verbi-software

35. Kuper A, Lingard L, Levinson W. Critically appraising qualitative research. BMJ. 2008;337:a1035.

36. Willems DL, Pols AJ. Goodness! The empirical turn in health care ethics. Medische Antropologie. 2010;2010(22):161-70.

37. Andersen PM, Abrahams S, Borasio GD, de Carvalho M, Chio A, Van Damme $P$, et al. EFNS guidelines on the clinical management of amyotrophic lateral sclerosis (MALS)--revised report of an EFNS task force. Eur J Neurol. 2012; 19(3):360-75.

38. Bede P, Oliver D, Stodart J, van den Berg L, Simmons Z, D OB, et al. Palliative care in amyotrophic lateral sclerosis: a review of current international guidelines and initiatives. J Neurol Neurosurg Psychiatry. 2011; 82(4):413-8.

39. Borasio GD, Voltz R. Palliative care in amyotrophic lateral sclerosis. J Neurol. 1997;244(Suppl 4):S11-7.

40. Janda M, Eakin EG, Bailey L, Walker D, Troy K. Supportive care needs of people with brain tumours and their carers. Support Care Cancer. 2006; 14(11):1094-103.

41. Tuck KK, Brod L, Nutt J, Fromme EK. Preferences of patients with Parkinson's disease for communication about advanced care planning. Am J Hosp Palliat Care. 2015;32(1):68-77.

42. Koopman WJ, Benbow CL, Vandervoort M. Top 10 needs of people with multiple sclerosis and their significant others. J Neurosci Nurs. 2006;38(5):369-73.

43. Somerset M, Campbell R, Sharp DJ, Peters TJ. What do people with MS want and expect from health-care services? Health Expect. 2001;4(1):29-37.

44. Walbert T. Palliative care, end-of-life care, and advance care planning in neurooncology. Continuum (Minneap Minn). 2017;23(6, Neuro-oncology):1709-26.

45. Aoun SM, Breen $L$, Howting D, Edis R, Oliver D, Henderson R, et al. Receiving the news of a diagnosis of motor neuron disease: what does it take to make it better? Amyotroph Lateral Scler Frontotemporal Degener. 2016;17(3-4):168-78.

46. Boersma I, Jones J, Carter J, Bekelman D, Miyasaki J, Kutner J, et al. Parkinson disease patients' perspectives on palliative care needs: what are they telling us? Neurol Clin Pract. 2016;6(3):209-19.

47. Buecken R, Galushko M, Golla H, Strupp J, Hahn M, Ernstmann N, et al. Patients feeling severely affected by multiple sclerosis: how do patients want to communicate about end-of-life issues? Patient Educ Couns. 2012;88(2):318-24.

48. Pace A, Dirven L, Koekkoek JAF, Golla H, Fleming J, Ruda R, et al. European Association for Neuro-Oncology (EANO) guidelines for palliative care in adults with glioma. Lancet Oncol. 2017;18(6):e330-e40.

49. Fox S, Cashell A, Kernohan WG, Lynch M, McGlade C, O'Brien T, et al. Palliative care for Parkinson's disease: patient and carer's perspectives explored through qualitative interview. Palliat Med. 2017;31(7):634-41. https://doi.org/10.1177/0269216316669922.

50. Saleem TZ, Higginson IJ, Chaudhuri KR, Martin A, Burman R, Leigh PN. Symptom prevalence, severity and palliative care needs assessment using the palliative outcome scale: a cross-sectional study of patients with Parkinson's disease and related neurological conditions. Palliat Med. 2013; 27(8):722-31.

51. Sterckx W, Coolbrandt A, Clement P, Borgenon S, Decruyenaere M, De Vleeschouwer $\mathrm{S}$, et al. Living with a high-grade glioma: a qualitative study of patients' experiences and care needs. Eur J Oncol Nurs. 2015; 19(4):383-90.

52. Cipolletta S, Gammino GR, Palmieri A. Illness trajectories in patients with amyotrophic lateral sclerosis: how illness progression is related to life narratives and interpersonal relationships. J Clin Nurs. 2017;26(23-24):5033-43.

53. Baile WF, Buckman R, Lenzi R, Glober G, Beale EA, Kudelka AP. SPIKES-A sixstep protocol for delivering bad news: application to the patient with cancer. Oncologist. 2000;5(4):302-11.

54. Triebel KL, Martin RC, Nabors LB, Marson DC. Medical decision-making capacity in patients with malignant glioma. Neurology. 2009;73(24):2086-92.

55. Bobholz JA, Rao SM. Cognitive dysfunction in multiple sclerosis: a review of recent developments. Curr Opin Neurol. 2003;16(3):283-8. 
56. Buter TC, van den Hout A, Matthews FE, Larsen JP, Brayne C, Aarsland D. Dementia and survival in Parkinson disease: a 12-year population study. Neurology. 2008;70(13):1017-22.

57. Habets EJ, Kloet A, Walchenbach R, Vecht CJ, Klein M, Taphoorn MJ. Tumour and surgery effects on cognitive functioning in high-grade glioma patients. Acta Neurochir. 2014;156(8):1451-9.

58. Langdon DW. Cognition in multiple sclerosis. Curr Opin Neurol. 2011;24(3):244-9.

59. Muslimovic D, Post B, Speelman JD, Schmand B. Cognitive profile of patients with newly diagnosed Parkinson disease. Neurology. 2005;65(8):1239-45.

60. Chaudhuri KR, Bhidayasiri R, van Laar T. Unmet needs in Parkinson's disease: new horizons in a changing landscape. Parkinsonism Relat Disord. 2016; 33(Suppl 1):S2-8.

61. Fruehwald S, Loeffler-Stastka H, Eher R, Saletu B, Baumhackl U. Depression and quality of life in multiple sclerosis. Acta Neurol Scand. 2001;104(5):257-61.

62. Benditt JO, Smith TS, Tonelli MR. Empowering the individual with ALS at the end-of-life: disease-specific advance care planning. Muscle Nerve. 2001; 24(12):1706-9.

63. Davison SN. Facilitating advance care planning for patients with end-stage renal disease: the patient perspective. Clin J Am Soc Nephrol. 2006;1 (5):1023-8.

64. Simpson C. Advance care planning in COPD: care versus "code status". Chron Respir Dis. 2012;9(3):193-204

65. Cheon SM, Ha MS, Park MJ, Kim JW. Nonmotor symptoms of Parkinson's disease: prevalence and awareness of patients and families. Parkinsonism Relat Disord. 2008;14(4):286-90.

66. King SJ, Duke MM, O'Connor BA. Living with amyotrophic lateral sclerosis/ motor neurone disease (ALS/MND): decision-making about 'ongoing change and adaptation'. J Clin Nurs. 2009;18(5):745-54

67. Montel S, Albertini L, Desnuelle C, Spitz E. Evolution of quality of life, mental health, and coping strategies in amyotrophic lateral sclerosis: a pilot study. J Palliat Med. 2012;15(11):1181-4.

68. Members of the MSitsCSG, Rieckmann P, Centonze D, Elovaara I, Giovannoni G, Havrdova E, et al. Unmet needs, burden of treatment, and patient engagement in multiple sclerosis: a combined perspective from the MS in the 21st century steering group. Mult Scler Relat Disord. 2018;19:153-60.

69. Aoun SM, Breen LJ, Edis R, Henderson RD, Oliver D, Harris R, et al. Breaking the news of a diagnosis of motor neurone disease: a national survey of neurologists' perspectives. J Neurol Sci. 2016;367:368-74.

70. Turner-Stokes L, Sykes N, Silber E, Khatri A, Sutton L, Young E. From diagnosis to death: exploring the interface between neurology, rehabilitation and palliative care in managing people with long-term neurological conditions. Clin Med (Lond). 2007;7(2):129-36.

71. O'Brien MR, Whitehead B, Jack BA, Mitchell JD. From symptom onset to a diagnosis of amyotrophic lateral sclerosis/motor neuron disease (ALS/MND): experiences of people with ALS/MND and family carers - a qualitative study. Amyotroph Lateral Scler. 2011;12(2):97-104.

72. Back AL, Arnold RM, Baile WF, Tulsky JA, Barley GE, Pea RD, et al. Faculty development to change the paradigm of communication skills teaching in oncology. J Clin Oncol. 2009;27(7):1137-41.

73. Berns SH, Camargo M, Meier DE, Yuen JK. Goals of care ambulatory resident education: training residents in advance care planning conversations in the outpatient setting. J Palliat Med. 2017;20(12):1345-51.

74. Merckaert I, Lienard A, Libert Y, Bragard I, Delvaux N, Etienne AM, et al. Is it possible to improve the breaking bad news skills of residents when a relative is present? A randomised study. Br J Cancer. 2013;109(10):2507-14.

75. Parikh PP, White MT, Buckingham L, Tchorz KM. Evaluation of palliative care training and skills retention by medical students. J Surg Res. 2017;211:172-7.

76. Lienard A, Merckaert I, Libert Y, Bragard I, Delvaux N, Etienne AM, et al. Is it possible to improve residents breaking bad news skills? A randomised study assessing the efficacy of a communication skills training program. $\mathrm{Br} J$ Cancer. 2010;103(2):171-7.

77. Galushko M, Golla H, Strupp J, Karbach U, Kaiser C, Ernstmann N, et al. Unmet needs of patients feeling severely affected by multiple sclerosis in Germany: a qualitative study. J Palliat Med. 2014;17(3):274-81.

78. Kluger BM, Fox S, Timmons S, Katz M, Galifianakis NB, Subramanian I, et al. Palliative care and Parkinson's disease: meeting summary and recommendations for clinical research. Parkinsonism Relat Disord. 2017:37:19-26.

79. Whitehead B, O'Brien MR, Jack BA, Mitchell D. Experiences of dying, death and bereavement in motor neurone disease: a qualitative study. Palliat Med. 2012;26(4):368-78

\section{Publisher's Note}

Springer Nature remains neutral with regard to jurisdictional claims in published maps and institutional affiliations.
Ready to submit your research? Choose BMC and benefit from:

- fast, convenient online submission

- thorough peer review by experienced researchers in your field

- rapid publication on acceptance

- support for research data, including large and complex data types

- gold Open Access which fosters wider collaboration and increased citations

- maximum visibility for your research: over $100 \mathrm{M}$ website views per year

At BMC, research is always in progress.

Learn more biomedcentral.com/submissions 